Norvège. Le consensus au cœur des réformes

Études de cas

Anne-Lise Høstmark Tarrou

\title{
CpenEdition
}

Journals

Édition électronique

URL : https://journals.openedition.org/ries/1258

DOI : $10.4000 /$ ries. 1258

ISSN : 2261-4265

Éditeur

France Education international

Édition imprimée

Date de publication : 1 décembre 2005

Pagination : 43-44

ISSN : 1254-4590

Référence électronique

Anne-Lise Høstmark Tarrou, « Norvège. Le consensus au cœur des réformes », Revue internationale d'éducation de Sèvres [En ligne], 40 I décembre 2005, mis en ligne le 17 novembre 2011, consulté le 05 juillet 2021. URL : http://journals.openedition.org/ries/1258; DOI : https://doi.org/10.4000/ries.1258

Ce document a été généré automatiquement le 5 juillet 2021

(c) Tous droits réservés 


\section{Norvège. Le consensus au cœur des réformes}

Études de cas

Anne-Lise Høstmark Tarrou

1 Dans tous les pays, l'éducation est issue d'une culture nationale et témoigne des valeurs constitutives de la société qui la porte. Le système éducatif, sa structure et son mode de financement, le contenu de l'enseignement et les méthodes de travail, en sont des témoins caractéristiques. Dans le même temps, l'éducation actuelle ne reste pas enfermée à l'intérieur de l'État-nation. Le développement rapide des nouvelles technologies d'information et de communication, la globalisation de l'économie et des échanges et la mobilisation du marché du travail, les échanges de connaissances et l'harmonisation des systèmes de notations influencent à présent l'éducation nationale dans tous les pays occidentaux.

\section{Une volonté d'adaptation}

2 Les grands axes de développement du système éducatif norvégien sont certainement spécifiques à la Norvège, même s'ils peuvent correspondre à des spécificités d'autres pays.

3 Cette école s'est, au fil des années, ouverte de plus en plus à toutes sortes d'élèves et a étendu, lors de la réforme de 1994, le droit légal de scolarité/formation au lycée à tous les jeunes jusqu'à l'âge de vingt ans. Nous observons une homogénéisation de la législation de l'enseignement secondaire et de la formation en entreprise, tendance déjà évidente lors de la réforme de 1994 et qui se renforce dans la réforme 2004, qui souligne la nécessité d'une ouverture encore plus large au monde du travail. Les utilisateurs de l'école, que ce soit les élèves ou les entreprises, publiques ou privées, manifestent de plus en plus d'exigences en ce qui concerne les objectifs et les résultats de l'école. Enfin dernier axe de plus en plus visible: une accélération de la fréquence des réformes scolaires à tous les niveaux de l'enseignement, sans doute à cause des enquêtes internationales comme PISA, mais aussi parce que le niveau d'éducation des 
salariés des entreprises est de plus en plus élevé (actuellement un tiers des salariés norvégiens ont une formation au niveau supérieur).

4 Nous cherchons tous à améliorer la qualité de l'éducation, nous visons tous à une meilleure efficacité du système éducatif et nous ressentons le besoin d'adapter l'éducation à la société actuelle, voire aux changements du monde du travail. Mais nos stratégies pour y parvenir ne sont souvent pas les mêmes, quoiqu'elles comportent aussi quelques points communs. Elles ne sont pas issues d'une culture internationale de l'éducation. Dans la pratique, les traits culturels nationaux semblent finalement prédominer.

\section{Consensus et continuité}

En Norvège, un plan cadre a été voté au Parlement en 1994 pour l'enseignement de base, pour l'enseignement secondaire, pour l'apprentissage dans les entreprises, pour la formation des adultes et pour les stages en académies populaires (folkehøgskolen). Ce plan a été présenté sous sept angles, comme autant de qualités à acquérir par sept hommes: l'homme qui cherche le sens; l'homme créatif; l'homme travailleur; l'homme de culture générale; l'homme de collaboration; l'homme conscient de l'environnement ; l'homme intégré qui réunit toutes ces qualités.

6 Les valeurs exprimées dans ce plan-cadre présenté par un ministère social-démocrate ont été réaffirmées par le Parlement en 2003, sur proposition d'un ministère de centredroit. Sur cette base de valeurs, une nouvelle réforme générale se met en place actuellement.

7 Le Rapport n 30 (2003-2004) intitulé «Culture pour apprendre » met l'accent sur la les connaissances comme ressources et comme force motrice, ainsi que sur la complexité et la pluralité plus grandes de la société. Il affirme que les compétences sont la principale réponse aux enjeux venant des entreprises. Les changements annoncés du système éducatif vont comprendre la mise en place d'objectifs définis au niveau national, la définition de responsabilités spécifiques, un accroissement de la liberté d'actions au niveau local.

Concernant le contenu de la formation, une simplification des programmes-cadres pour chaque matière/métier va être mise en place. Les objectifs pour les compétences à acquérir par l'élève/l'apprenti dans chaque matière/métier et les aptitudes fondamentales, particulièrement importantes pour le développement professionnel et personnel des élèves, sont identifiées comme cinq savoirs : savoir s'exprimer à l'oral ; savoir lire; savoir s'exprimer à l'écrit; savoir compter; savoir utiliser les outils manuels. Ces aptitudes de base sont identifiées pour pouvoir acquérir et développer des connaissances et du savoir au sein des matières/métiers; communiquer et interagir avec les autres à une large échelle (dans l'enseignement, à l'emploi, au travail et au niveau personnel). Le rapport souligne en même temps que le fait de décrire ainsi les objectifs de compétences et les aptitudes fondamentales ne signifie nullement qu'il faut renoncer à mettre l'accent sur les développements multiples et personnels des élèves et des apprentis, mais que les matières/métiers à apprendre sont un point de rencontre entre les aptitudes de base et la culture générale. 
9 Des groupes d'experts représentant les professionnels du secteur et les différents partenaires sociaux développent actuellement des programmes-cadres pour chaque matière/métier. Ce travail est dirigé par la direction de l'Éducation. En Norvège, l'enjeu est le suivant: les notions d'égalité et de dialogue social ont constitué un terrain favorable dans la société pour un partenariat entreprises/écoles fondé sur une compréhension mutuelle construite sur la base de négociations paritaires. Reste à savoir s'il est possible de maintenir le cadre de la société-providence capable d'affronter la compétition internationale en ne lésant personne.

\section{INDEX}

Index géographique : Norvège

\section{AUTEUR}

\section{ANNE-LISE HøSTMARK TARROU}

Professeur, docteur en philosophie, directrice du Programme for Research on Education and Work, Akershus University College, membre du conseil scientifique de la Revue internationale d'éducation de Sèvres. 